\title{
Protective Effect of Nilvadipine on Focal Cerebral Ischemia in Spontaneously Hypertensive Rats
}

\author{
Shingo KaWAmURA, Yiping LI, Mitsuru ShIRASAWA*, \\ Nobuyuki YASUI, and Hitoshi FUKASAWA* \\ Departments of Surgical Neurology and ${ }^{*}$ Pathology, Research Institute for Brain \\ and Blood Vessels-AKITA, Akita
}

\begin{abstract}
The protective effect of nilvadipine, a $\mathrm{Ca}^{2+}$ antagonist, on cerebral ischemia was investigated in spontaneously hypertensive rats. The 12-week-old animals were treated for 7 days with either nilvadipine or vehicle using osmotic pumps implanted subcutaneously. Group 1 animals $(\mathbf{n}=10)$ received the vehicle, and Group $2(n=10)$ and 3 animals $(n=10)$ received 1 and $3 \mathrm{mg} / \mathrm{kg} / \mathrm{day}$ nilvadipine, respectively. The left middle cerebral artery was occluded under halothane anesthesia on the 6th day of treatment, and neuropathological outcomes were quantified 24 hours later. The systolic blood pressure measured before occlusion decreased to $137 \pm 9 \mathrm{mmHg}$ (Group 2) and $130 \pm 9 \mathrm{mmHg}$ (Group 3), compared to $189 \pm 12 \mathrm{mmHg}$ for Group $1(\mathrm{p}<0.05)$. The percentage infarct volumes in Groups $1-3$ were $39 \pm 3 \%, 37 \pm 2 \%$, and $34 \pm 3 \%$, respectively ( $p<0.05$, Groups $1 v s$. 3 ). Therefore, nilvadipine decreased the infarct size dose-dependently. Nilvadipine has a protective effect against cerebral ischemia in rats with chronic hypertension. Neuropathological findings suggest that nilvadipine may act at the ischemic penumbra. Nilvadipine may have the additional benefit of reducing the consequences of a possible later stroke in patients with hypertension (one of the risk factors for stroke).
\end{abstract}

Key words: $\mathrm{Ca}^{2+}$ entry blocker, protective effect, focal cerebral ischemia, middle cerebral artery occlusion, spontaneously hypertensive rats

\section{Introduction}

$\mathrm{Ca}^{2+}$ entry blockers may have protective effects against cerebral ischemia. Recent evidence suggests that these agents can attenuate ischemic neuronal injury through direct effects on neurons by preventing an excessive $\mathrm{Ca}^{2+}$ influx into the cytoplasmic and mitochondrial compartments ${ }^{11,12)}$; and dilation of cerebral vessels, resulting in an increase of the cerebral blood flow. ${ }^{2,6)}$

Our previous study showed that nilvadipine, a dihydropyridine $\mathrm{Ca}^{2+}$ entry blocker, reduces infarct size in normotensive rats with occlusion of the middle cerebral artery (MCA). ${ }^{7}$ Nilvadipine is used mainly for treating patients with hypertension, which is one of the risk factors for stroke. Knowledge about whether nilvadipine has the additional benefit of reducing the consequences of a possible later stroke in hypertensive animals is of great value, because it requires long-term administration

Received April 18, 1995; Accepted October 5, 1995 and so would be present at the time of stroke onset.

The present study investigated the protective effect of nilvadipine on focal cerebral ischemia after treating high blood pressure in spontaneously hypertensive (SH) rats. The rat model of MCA occlusion used an intraluminal thread technique, ${ }^{7,9}$ and assessed the neuropathological outcomes.

\section{Materials and Methods}

\section{General preparation}

Thirty 12 -week-old male SH rats, weighing 230 $310 \mathrm{~g}$ (mean $\pm \mathrm{SD} 273 \pm 24 \mathrm{~g}$ ) (Charles River Japan, Inc., Atsugi, Kanagawa), had free access to food and water during all procedures. Both arterial blood pressure and heart rate were measured without anesthesia, using the tail-cuff method with a Rat Manometer-Tachometer TK350 (Unicom, Inc., Chiba). Both measurements were taken three times (within $24 \mathrm{hrs}$ before both drug treatment and surgery for MCA occlusion) for each rat, and the mean values were calculated. Body weight had in- 
creased to $260-330 \mathrm{~g}(293 \pm 20 \mathrm{~g})$ by the time of MCA occlusion.

\section{Drug administration}

Nilvadipine was dissolved in polyethylene glycol $(1.25$ or $4.0 \mathrm{mg} / \mathrm{ml})$. Nilvadipine and/or vehicle was administered subcutaneously at $10 \mu \mathrm{l} / \mathrm{hr}$ using an osmotic pump (Alzet 2ML1; Alza Corporation, Palo Alto, Cal., U.S.A.). The pump was implanted subcutaneously on the back, slightly posterior to the scapulae, under $1.5 \%$ halothane anesthesia. All animals were treated for 7 days before sacrifice.

Animals were randomly divided into three groups (10 rats per group). Group 1 (control) animals were treated with only vehicle. Group 2 and 3 animals were treated with nilvadipine ( 1 and $3 \mathrm{mg} / \mathrm{kg}$ body weight/day, respectively). All animals underwent MCA occlusion on the 6th day of the treatment.

\section{Induction of ischemia}

Anesthesia was induced using 4\% halothane, then switched to $1.5 \%$ during the skin incision, and maintained with $1 \%$ halothane. Atropine sulfate $(0.25 \mathrm{mg}$ per rat, s.c.) was used for premedication. The animals were allowed to spontaneously breathe a mixture of nitrous oxide/oxygen $(70 \% / 30 \%)$. Rectal temperature was maintained at $37^{\circ} \mathrm{C}$ with a heating pad.

The left MCA was occluded using the method described previously. ${ }^{7,9)}$ The left external carotid artery was isolated via a ventral midline neck incision. The origin of the pterygopalatine artery was occluded temporally with a microclip, so that the intraluminal thread (below) was never introduced erroneously into the pterygopalatine artery. Next, the external carotid artery was ligated and cut, and a 3-0 nylon thread (with the tip rounded and polished by sandpaper) was introduced into the arterial stump. The nylon thread was advanced into the internal carotid artery. When the tip of the thread entered the proximal segment of the anterior cerebral artery, the origin of the MCA was occluded by the thread. The skin incision was closed, and the animals were returned to their cages.

\section{Neuropathology}

Twenty-four hours following MCA occlusion, spontaneously respiring animals were anesthetized with pentobarbital sodium $(45 \mathrm{mg} / \mathrm{kg}$ body weight, i.p.). Rectal temperature was controlled at $37^{\circ} \mathrm{C}$. After heparinization, transcardiac perfusion-fixation was performed with $10 \%$ buffered formalin, and the brains were stored in $15 \%$ formalin. The forebrains were embedded in paraffin wax, and coronal sections
( $5 \mu \mathrm{m}$ thick) were cut, stained with $\mathrm{HE}$, and examined by light microscopy. Area measurements were carried out at eight coronal levels at $1.5 \mathrm{~mm}$ intervals, with the first level was $2.5 \mathrm{~mm}$ posterior to the frontal tip. Areas of infarction were measured using an image analyzer (Texture Analyzing System, Leitz, Wetzlar, Germany). Measurements were performed separately for the striatum, the pallium, and each hemisphere. The volume of infarction was calculated with a computer program by summing the infarcted areas of sequential sections, and by multiplying the sum with the total interval thickness between sections. The volume of each hemisphere between the eight levels was also calculated. The infarct volume was expressed both as an absolute value $\left(\mathrm{mm}^{3}\right)$ and as a percentage of the total cerebral volume.

Prior to perfusion-fixation, venous blood was aspirated from the right atrium of the heart, and the plasma concentration of nilvadipine $(\mathrm{pCN})$ was measured using gas chromatography, as described previously. ${ }^{7}$

\section{Statistical analysis}

All data are expressed as mean \pm SD. The blood pressure and heart rate before and after treatment were compared in each group by the paired Student's t-test. Scheffe's multiple comparison test was used for inter-group comparison. The $\mathrm{pCN}$ values were compared between Groups 2 and 3 by the unpaired Student's t-test. A p value $<0.05$ was considered significant.

\section{Results}

\section{Arterial blood pressure and heart rate}

Systolic blood pressure and heart rate before both drug treatment and surgery for MCA occlusion are summarized in Table 1. The blood pressures of Group 1 were stable, but were reduced significantly in Groups 2 and 3 by the treatment $(p<0.05)$. The differences in blood pressure between Groups 2 and 3 were not significant. Heart rates were similar among all groups, and were not affected by either treatment.

\section{Neuropathological outcomes}

Infarct volumes following MCA occlusion are summarized in Table 2. The total and percentage infarct volumes decreased in a dose-dependent manner: the difference between Groups 1 and 3 was significant $(p<0.05)$. The decrease was primarily due to the decrease of infarct volume in the pallium. The differences in total infarct volumes between Groups 1 and $2(p<0.08)$, and between Groups 2 and $3(p<0.09)$ were not significant. To show where the infarction 
Table 1 Arterial blood pressure and heart rate in unanesthetized SH rats

\begin{tabular}{cccccc}
\hline & \multicolumn{2}{c}{ Before treatment } & \multicolumn{2}{c}{ Before MCA occlusion } \\
\cline { 2 - 3 } Group (n) & $\begin{array}{c}\text { SBP } \\
\text { (mmHg) }\end{array}$ & $\begin{array}{c}\text { HR } \\
\text { (beats/min) }\end{array}$ & & $\begin{array}{c}\text { SBP } \\
\text { (mmH) }\end{array}$ & $\begin{array}{c}\text { HR } \\
\text { (beats } / \text { min) }\end{array}$ \\
\hline $1(10)$ & $191 \pm 13$ & $446 \pm 47$ & & $189 \pm 12$ & $423 \pm 37$ \\
$2(10)$ & $190 \pm 15$ & $468 \pm 38$ & & $137 \pm 9^{*}$ & $460 \pm 45$ \\
$3(10)$ & $199 \pm 13$ & $456 \pm 18$ & & $130 \pm 9^{*}$ & $440 \pm 28$ \\
\hline
\end{tabular}

Values are mean $\pm \mathrm{SD} . \quad{ }^{*} \mathrm{p}<0.01$ vs. before treatment (paired t-test), and $\mathrm{p}<0.05$ vs. Group 1 before MCA occlusion (Scheffe's test). HR: heart rate, n: number of animals, SBP: systolic blood pressure.

Table 2 Infarct volume 24 hours after onset of MCA occlusion

\begin{tabular}{ccccc}
\hline Group (n) & $\begin{array}{c}\text { Striatum } \\
\left(\mathrm{mm}^{3}\right)\end{array}$ & $\begin{array}{c}\text { Pallium } \\
\left(\mathrm{mm}^{3}\right)\end{array}$ & $\begin{array}{c}\text { Total } \\
\left(\mathrm{mm}^{3}\right)\end{array}$ & $\begin{array}{c}\text { Percent infarct } \\
\text { volume }\end{array}$ \\
\hline $1(10)$ & $51 \pm 8$ & $193 \pm 11$ & $244 \pm 15$ & $39 \pm 3$ \\
$2(10)$ & $49 \pm 7$ & $174 \pm 15^{*}$ & $223 \pm 20$ & $37 \pm 2$ \\
$3(10)$ & $45 \pm 5$ & $159 \pm 19^{*}$ & $204 \pm 22^{*}$ & $34 \pm 3^{*}$ \\
\hline
\end{tabular}

Values are mean $\pm \mathrm{SD} .{ }^{*} \mathrm{p}<0.05$ vs. Group 1 (Scheffe's test). n: number of animals.

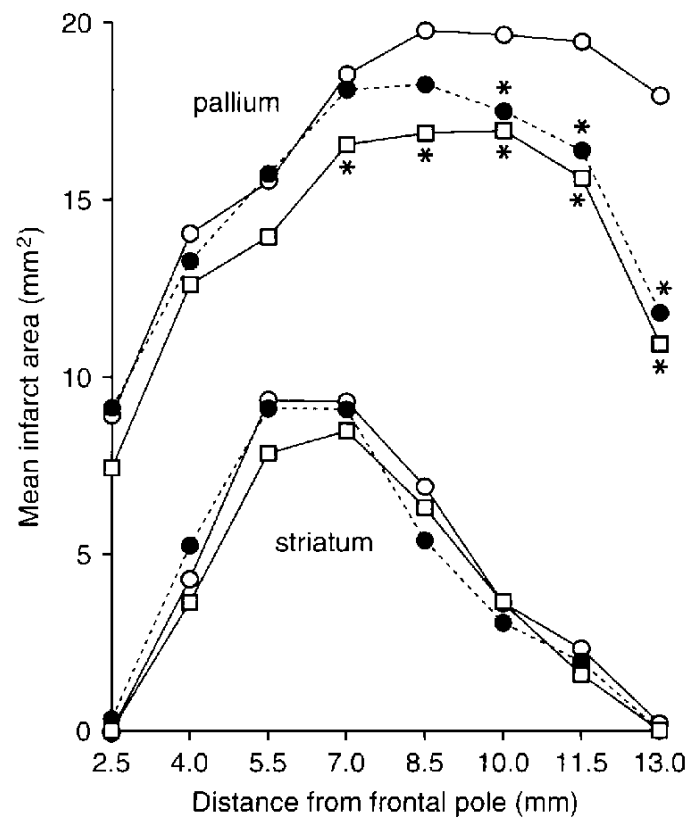

Fig. 1 Mean infarct areas in each section. ${ }^{*} \mathrm{p}<0.05$ vs. Group 1 (Scheffe's test). $O$ : Group 1 (control), $\bullet$ : Group $2(1 \mathrm{mg} / \mathrm{kg}$ /day nilvadipine), $\square$ : Group 3 ( $3 \mathrm{mg} / \mathrm{kg} /$ day nilvadipine). size had decreased, the mean infarct areas in each coronal section of each group are indicated in Fig. 1. The infarct size decreased significantly in the posterior (occipital) periphery of the pallium.

\section{Value of $\mathrm{pCN}$}

Nilvadipine was not detected in plasma obtained from Group 1. The pCN of Group 3 (14.5 $\pm 3.9 \mathrm{ng} /$ $\mathrm{ml})$ was 2.5 times greater than that of Group 2 $(5.8 \pm 0.8 \mathrm{ng} / \mathrm{ml})(\mathrm{p}<0.001)$.

\section{Discussion}

Our results clearly demonstrate that nilvadipine reduces the infarct size dose-dependently after treatment of high blood pressure in SH rats, indicating that nilvadipine provides a protective effect for ischemic stroke even after the development of chronic hypertension. The protective effect of dihydropyridine $\mathrm{Ca}^{2+}$ entry blockers in $\mathrm{SH}$ rats has been reported using isradipine, ${ }^{13)}$ nimodipine, ${ }^{6)}$ and nilvadipine, ${ }^{14)}$ although the durations of drug administration $(<5 \mathrm{hrs})$ were considerably shorter than that in our study (7 days).

Several mechanisms have been proposed for the protective effects of $\mathrm{Ca}^{2+}$ entry blockers against ischemic brain injury. ${ }^{15)}$ The drugs can preserve neuronal function by preventing the accumulation of intracellular $\mathrm{Ca}^{2+} .{ }^{1,5)}$ Moreover, these agents can induce relaxation of vascular smooth muscle, ${ }^{2)}$ and subsequently increase cerebral blood flow. ${ }^{4,6)}$ Kawamura and Yasui, ${ }^{8)}$ using a closed cranial window technique in rats, observed that nilvadipine dilates pial arterioles in vivo. In our present study, the observed decrease in infarct size in the posterior periphery of the pallium might have resulted from the presence of collateral circulation from the posterior cerebral artery. This area appears to correlate anatomically to the ischemic penumbra. Nilvadipine may act at the penumbra by increasing the blood flow and/or by preventing cell death by direct action on neurons.

In contrast, the infarct size in the anterior periphery of the pallium (possibly perfused by the collateral blood flow from the anterior cerebral artery) did not decrease significantly (Fig. 1). This contradication may be related to our MCA occlusion procedures. Our rat model occluded the internal carotid artery at its terminal portion. The ipsilateral anterior cerebral artery was also occluded at its origin. The internal carotid artery occlusion possibly affects the cerebral blood flow in the territory of the anterior cerebral artery more than MCA occlusion alone. The collateral blood flow from the anterior cerebral artery to the ischemic MCA areas can be considered as coming 
from the contralateral carotid artery through a communication between the bilateral anterior cerebral arteries (by way of cross filling). In contrast, the ipsilateral posterior cerebral artery must have direct leptomeningeal anastomoses with the occluded MCA branches, because this artery is intact. The topographical extent of infarction may be influenced by the difference in the collateral route. Our results suggest that nilvadipine reduces ischemic brain damage in the penumbra, where the patent posterior cerebral artery supplies the leptomeningeal collateral blood flow. The infarct size in the ischemic core (the striatum) did not decrease.

There was no significant difference between the blood pressures of Groups 2 and 3, although the plasma concentration of nilvadipine increased almost proportionally to the doses administered. The reason why is unclear. In our previous study, in which nilvadipine reduced infarct size dose-dependently in normotensive rats, blood pressures remained at about the same level 24 hours after a single dose of either 1.0 or $3.2 \mathrm{mg} / \mathrm{kg}$ nilvadipine. ${ }^{7)}$ It is unlikely that the observed protective effect against cerebral ischemia is directly related to the decrease in arterial blood pressure. Similar findings have been observed with a different antihypertensive drug, ${ }^{16}$ ) which may restore normal endothelial function, resulting in an increase of the cerebral blood flow reserve. ${ }^{3)}$

Another of our studies has shown that nilvadipine is effective in decreasing infarct volume in normotensive rats when administered up to 3 hours following MCA occlusion. ${ }^{10)}$ Other workers have also shown that nilvadipine decreases the infarct size when given intraperitoneally within 1 hour following MCA occlusion in SH rats. ${ }^{14)}$ Therefore, in addition to the protective effect, nilvadipine may have a potential therapeutic effect on cerebral ischemia.

Nilvadipine reduces ischemic neuronal injury following MCA occlusion after treating chronic hypertension in $\mathrm{SH}$ rats. Our results suggest that the drug may act at the ischemic penumbra. This antihypertensive drug may have the additional benefit of reducing the consequences of a possible later stroke in hypertensive patients receiving long-term treatment.

\section{Acknowledgments}

The technical assistance of $Y$. Ito and R. Sato, and the secretarial assistance of $Y$. Tozawa, are gratefully acknowledged. Nilvadipine (Lot No. 0140) was obtained from Fujisawa Pharmaceutical Co. Ltd., Osaka.

\section{References}

1) Abe K, Kogure K, Watanabe T: Prevention of ischemic and postischemic brain edema by a novel calcium antagonist (PN200-110). J Cereb Blood Flow Metab 8: 436-439, 1988

2) Brandt L, Ljunggren $B$, Andersson KE, Edvinsson L, MacKenzie E, Tamura A, Teasdale G: Effects of topical application of a calcium antagonist (nifedipine) on feline cortical pial microvasculature under normal conditions and in focal ischemia. $J$ Cereb Blood Flow Metab 3: 44-50, 1983

3) Clozel M, Kuhn H, Hefti F: Effects of angiotensin converting enzyme inhibitors and hydralazine on endothelial function in hypertensive rats. Hypertension 16: $532-540,1990$

4) Furuichi Y, Takakura S, Satoh H, Mori J, Kohsaka M: The effect of nilvadipine, a dihydropyridine type calcium channel blocker, on local cerebral blood flow in rats. Jpn J Pharmacol 58: 457-460, 1992

5) Hadani $M$, Young $W$, Flamm ES: Nicardipine reduces calcium accumulation and electrolyte derangements in regional cerebral ischemia in rats. Stroke 19: 1125-1132, 1988

6) Jacewicz M, Brint S, Tanabe J, Wang XJ, Pulsinelli WA: Nimodipine pretreatment improves cerebral blood flow and reduces brain edema in conscious rats subjected to focal cerebral ischemia. $J$ Cereb Blood Flow Metab 10: 903-913, 1990

7) Kawamura S, Shirasawa M, Fukasawa H, Yasui N: Attenuated neuropathology by nilvadipine after middle cerebral artery occlusion in rats. Stroke 22: 5155,1991

8) Kawamura S, Yasui N: In vivo effects of the $\mathrm{Ca}^{2+}$ entry blocker nilvadipine on brain surface microvessels in rats. Neurol Med Chir (Tokyo) 34: 663-667, 1994

9) Kawamura S, Yasui N, Shirasawa M, Fukasawa $H$ : Rat middle cerebral artery occlusion using an intraluminal thread technique. Acta Neurochir (Wien) 109: 126-132, 1991

10) Li $Y$, Kawamura $S$, Yasui $N$, Shirasawa $M$, Fukasawa H: Therapeutic effects of nilvadipine on rat focal cerebral ischemia. Exp Brain Res 99: 1-6, 1994

11) Meyer FB, Anderson RE, Yaksh TL, Sundt TM Jr: Effect of nimodipine on intracellular brain $\mathrm{pH}$, cortical blood flow, and EEG in experimental focal cerebral ischemia. $J$ Neurosurg 64: 617-626, 1986

12) Rosenblum WI: Effects of calcium channel blockers on pial vascular responses to receptor mediated constrictors. Stroke 15: 284-287, 1984

13) Sauter A, Rudin M, Wiederhold KH: Reduction of neural damage in irreversible cerebral ischemia by calcium antagonists. Neurochem Pathol 9: 211-236, 1988

14) Shiino A, Matsuda $M$, Susumu $T$, Handa J: Effects of the calcium antagonist nilvadipine on focal cerebral ischemia in spontaneously hypertensive rats. 
Surg Neurol 35: 105-110, 1991

15) Siesjö BK: Pathophysiology and treatment of focal cerebral ischemia. Part II: Mechanisms of damage and treatment. $J$ Neurosurg 77: 337-354, 1992

16) Véniant $M$, Clozel JP, Kuhn H, Clozel M: Protective effect of cilazapril on the cerebral circulation. $J$ Cardiovasc Pharmacol 19 [Suppl 6]: S94-S99, 1992
Address reprint requests to: S. Kawamura, M.D., Department of Surgical Neurology, Research Institute for Brain and Blood Vessels-AKITA, 6-10 Senshukubota-machi, Akita 010, Japan. 